\title{
APLICAÇÃO DO TESTE DE RAIOS X NO ESTUDO DA MORFOLOGIA INTERNA E DA QUALIDADE FISIOLÓGICA DE AQUÊNIOS DE ARNICA (Lychnophora pinaster Mart.) ${ }^{1}$
}

\author{
PAULO RÉGIS BANDEIRA DE MELO², JOÃO ALMIR OLIVEIRA³, MARIA LAENE MOREIRA DE CARVALHO4, \\ RENATO MENDES GUIMARÃES ${ }^{5}$, BRUNO DE OLIVEIRA CARVALHO ${ }^{6}$
}

\begin{abstract}
RESUMO - O teste de raios $\mathrm{X}$ vem sendo empregado em programas de qualidade e como auxiliar nos estudos morfológicos e fisiológicos de sementes de diversas espécies. A arnica (Lychnophora pinaster Mart.) é uma espécie medicinal que apresenta um número elevado de aquênios cheios ou mal formados por ocasião da frutificação, o que dificulta a produção de sementes necessária para o suprimento de uma demanda cada vez maior, pela indústria farmacêutica. Para verificar o efeito do estádio de maturação de aquênios de arnica na qualidade fisiológica das sementes e a eficiência do teste de raios $\mathrm{X}$ na separação de sementes mal formadas, foram coletados, no mês de dezembro de 2003, aquênios provenientes de uma população de plantas do município de Itumirim, MG. Na coleta, foram considerados os capítulos cujos aquênios apresentavam o papus interno aderido, estádio menos maduro e com papus interno ausente, aquênios mais maduros já em dispersão. Após a coleta, os aquênios foram submetidos à secagem, pré-limpeza e separados com auxílio de um soprador vertical. Os aquênios foram dispostos em placas de acrílico transparente sobre fita adesiva de dupla face, radiografados e separados em três categorias, de acordo com a morfologia interna visualizada na radiografia em cheios, mal formados e vazios; em seguida foram submetidos ao teste de germinação por um período de 90 dias, em BOD regulada à temperatura alternada de $20-30^{\circ} \mathrm{C}$ e fotoperíodo de 12 horas. Foram avaliados o índice de velocidade e a porcentagem final de germinação. Os aquênios remanescentes foram submetidos ao teste de tetrazólio para verificação da sua viabilidade. O teste de raios X na intensidade de $30 \mathrm{Kv}$ por 45 segundos é eficiente na separação dos aquênios conforme sua morfologia interna. No estádio de maturação dos capítulos com aquênios sem o papus interno são obtidas sementes de arnica de qualidade fisiológica superior.
\end{abstract}

Termos para indexação: semente, análise de imagens, maturação, germinação, planta medicinal.

\section{APPLICATION OF THE X-RAY TEST TO STUDY THE INTERNAL MORPHOLOGY AND PHYSIOLOGICAL QUALITY OF ARNICA SEEDS (Lychnophora pinaster Mart.).}

\begin{abstract}
The X-ray test is used in seed quality programs to assist morphological and physiological evaluations. Arnica (Lychnophora pinaster Mart.) is considered a medicinal species that has a remarkable number of badly formed seeds at the time of fruit dispersion. Thus, the objective of this study was to verify the influence of the maturation stages on the physiological quality of
\end{abstract}

${ }^{1}$ Submetido em 20/08/2008. Aceito para publicação em 21/10/2008. Parte da dissertação de Mestrado apresentada pelo primeiro autor à Universidade Federal de Lavras (UFLA).

${ }^{2}$ Eng. Agr., M.Sc., Doutorando, FCAV/UNESP, CEP 14884-900, Jaboticabal - SP, e-mail: pauloregmelo@yahoo.com.br

${ }^{3}$ Biólogo, Dr., Prof., UFLA, Cx. Postal 3037, 37200-000, Lavras-MG, e-mail: jalmir@ufla.br
${ }^{4}$ Eng. Agr., Dr., Prof., UFLA, Cx. Postal 3037, 37200-000, Lavras-MG, e-mail: mlaenemc@ufla.br

${ }^{5}$ Eng. Agr., Dr., Prof., UFLA, Cx. Postal 3037, 37200-000, Lavras-MG, e-mail: renatomg@ufla.br

${ }^{6}$ Graduando em Agronomia, UFLA, Cx. Postal 3037, 37200-000, LavrasMG. 


\begin{abstract}
Arnica seeds by the X-ray test. The seeds used were collected in December 2003 from a natural population in the district of Itumirim, State of Minas Gerais, Brazil. At seed collection the following were considered: the capitulum in which the seeds showed jointed internal papus, less mature stage, without internal papus and seeds that were dispersing. After collection the seeds were dried, cleaning and separated with a vertical blower. The seeds were placed in acrylic transparent plates, radiographed and separated into three categories, full, badly formed and empty seeds according to the internal morphology observed on the radiographs. The time and intensity used during the X-ray test were previously tested. Four replications of 50 seeds for each treatment were used. The seeds were placed in a gerbox on paper towel and kept for 90 days in an incubator (BOD) adjusted at alternating temperature $\left(20-30^{\circ} \mathrm{C}\right)$ and 12 -hour photoperiod. The parameters evaluated were speed of germination and final germination percentage. The remaining seeds were subjected to the tetrazolium test to verify seed viability. The X-ray test was shown to be effective for separating the seeds into categories based on their internal morphology. The radiation of $30 \mathrm{Kv}$ for 45 seconds allowed visualization of the internal structures of the seeds. The capitulum maturation stage with seeds without internal papus at the time of dispersion was the best for seed collection.
\end{abstract}

Index terms: seed, image analysis, maturation, germination, medicinal plant

\section{INTRODUÇÃO}

A arnica (Lychnophora pinaster Mart.) é uma espécie da família Asteraceae, natural de campos rupestres, considerada endêmica e ameaçada de extinção. Possui folhas e flores aromáticas com propriedades medicinais, cuja ação farmacológica predominante ocorre no sistema circulatório. $\mathrm{Na}$ medicina popular é usada como antiinflamatório, anestésico, cicatrizante, para traumatismos, contusões e picadas de insetos, como descrito por Rodrigues e Carvalho (2001).

Conforme Semir (1991), aquênios de arnica encontramse em subcapítulos de capítulos, apresentando papus internos e externos como estrutura de dispersão. Silva (1994), estudando a fenologia da arnica, separou a frutificação em três fases distintas: após antese e simultaneamente à senescência das flores, aquênios com papus internos presentes e aquênios com papus internos ausentes, já em dispersão.

Devido às variações ambientais e à dificuldade de mensuração, em dias, para a sucessão de eventos relacionados às fases fenológicas, como florescimento e frutificação, a determinação da maturidade fisiológica e do ponto de colheita ideal para as sementes de arnica também pode ser dificultada. Desta forma, há necessidade da associação de caracteres morfológicos da semente, que sejam de fácil observação e que possibilitem uma definição precisa desta maturidade e, conseqüentemente, do potencial fisiológico do lote.
O teste de raios X, criado por Simak e Gustafsson (1953), vem sendo empregado em programas de qualidade pela "International Seed Testing Association" (ISTA) e como auxiliar nos estudos morfológicos e fisiológicos para diversas espécies. Trata-se de um teste não destrutivo de fácil e rápida aplicação, cuja radiação emitida não afeta as sementes (Simak e Gustafsson, 1953; Bino et al., 1993).

A qualidade da imagem obtida, permanentemente formada no filme radiográfico, varia em função da espessura, densidade, composição da semente e comprimento de onda que as sementes foram submetidas (Bino et al., 1993), bem como do tempo de exposição das sementes à radiação, medida em quilovoltagem $(\mathrm{Kv})$ e sensibilidade do filme radiográfico. Assim, após a disposição das sementes sobre o filme e subseqüente exposição à radiação, formam-se imagens claras nas regiões mais densas, as quais os raios não atravessam, e imagens escuras nas regiões menos densas (ISTA, 1999).

Carvalho e Oliveira (2006) ressaltaram que, embora não resolva todos os problemas de avaliação da qualidade da semente, a técnica radiográfica, similarmente às áreas médicas ou industriais, possibilita diagnose rápida e não destrutiva, na maioria dos casos, fornecendo informações relevantes para o trabalho científico e controle de qualidade de sementes.

Com a percepção da utilização potencial do teste de raios $\mathrm{X}$ para diversas finalidades, acentuam-se os estudos para determinar as melhores condições de exposição das 
sementes, de diversas espécies, à radiação. Oliveira et al. (2003), utilizando um aparelho Faxitron, Hewlett-Packard (modelo 43855A), regulado a $25 \mathrm{Kv} / 60$ segundos, obtiveram nítida visualização de danos internos em sementes de Peltophorium dubium (canafístula). Oliveira et al. (2004), expondo sementes de Tabebuia spp (ipê) a $55 \mathrm{Kv} / 25$ segundos, observaram que defeitos internos detectados nas radiografias afetam a germinação dessas sementes reduzindo, assim, a qualidade do lote. Utilizando $30 \mathrm{Kv} / 45$ segundos, Tonetti et al. (2006) obtiveram êxito na visualização e conseqüente separação das sementes de Eremanthus erythropappus (candeia) nas categorias cheias, mal formadas e vazias. Machado e Cicero (2003) detectaram danos e anormalidades em embriões de Lithraea molleoides (aroeira-branca) em um aparelho Faxitron, Hewlett-Packard (modelo MX-20), regulado a $13 \mathrm{Kv} / 5$ minutos, e ressaltaram que a técnica de raios $\mathrm{X}$ pode auxiliar no descarte dessas sementes visando melhorar a germinação do lote. A utilização eficiente do teste de raios X, segundo Carvalho e Oliveira (2006) depende da sua adequação, espécie, bem como do tipo de dano a ser detectado nas sementes.

Dessa forma, o presente trabalho teve por objetivo verificar o efeito do estádio de maturação de aquênios de arnica e a eficiência do teste de raios X para determinar a sua qualidade.

\section{MATERIAL E MÉTODOS}

O presente trabalho foi conduzido com sementes de arnica provenientes do município de Itumirim, MG, coletadas no mês de dezembro de 2003.

A coleta dos aquênios foi efetuada em plantas adultas com tamanho superior a um metro de altura, sendo os capítulos cortados com tesoura, em diversas posições nas plantas, e acondicionados em sacos plásticos com capacidade para 20 litros, até a determinação do grau de umidade.

Foram realizadas quatro coletas em dias distintos, sendo as duas primeiras referentes ao estádio cujo papus interno, estrutura de dispersão, apresentava-se aderido aos aquênios presentes nos capítulos (Estádio 1). As coletas subsequentes referiram-se ao estádio em que não havia mais a presença de papus interno, sendo que os aquênios já se encontravam em dispersão (Estádio 2). As Figuras 1 e 2 ilustram estes estádios.
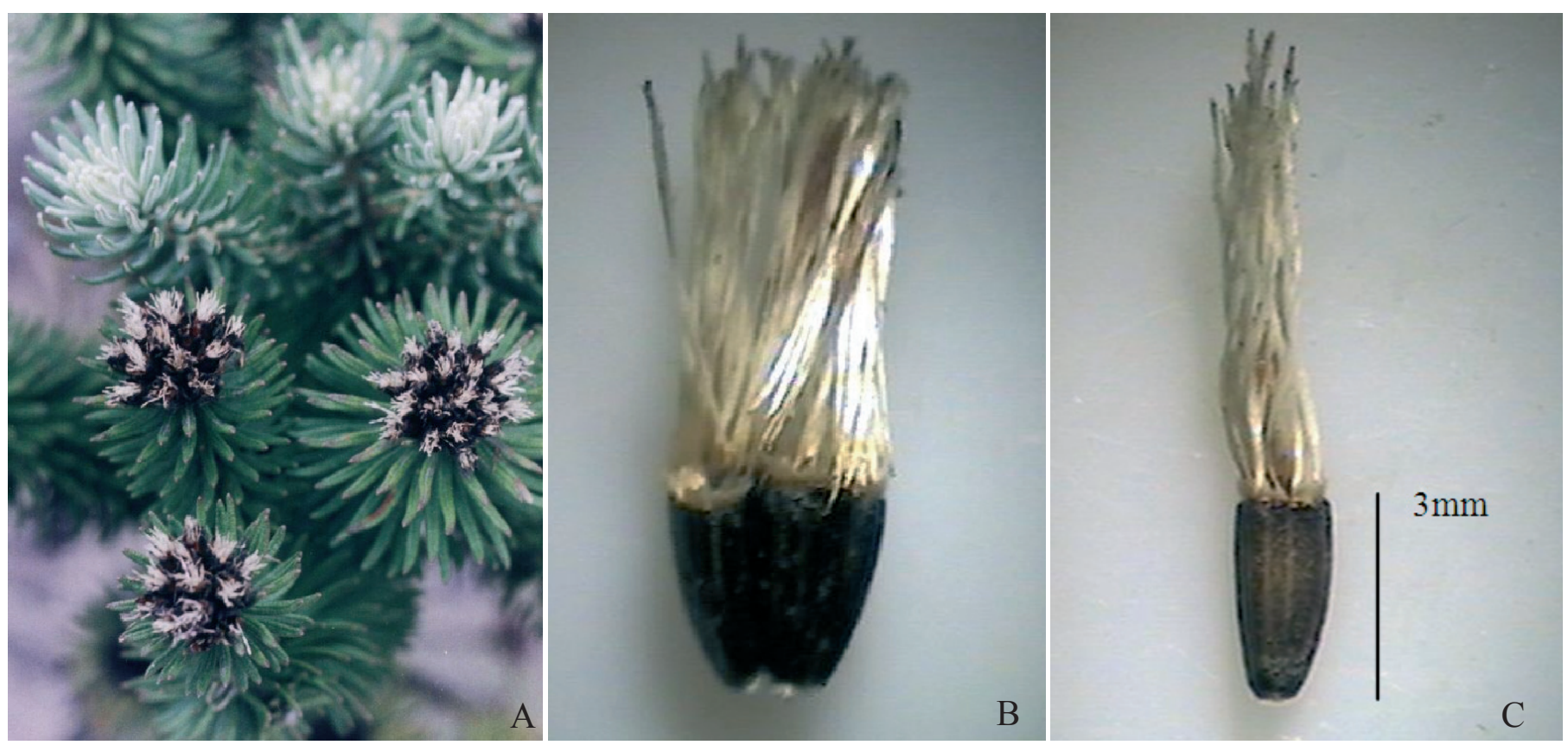

FIGURA 1. Caracterização do estádio 1 de coleta de aquênios de Lychnophora pinaster (arnica): capítulos com papus interno presente (A); aquênios agrupados, com papus interno aderido, formando subcapítulo (B); aquênio com papus interno aderido (C). 

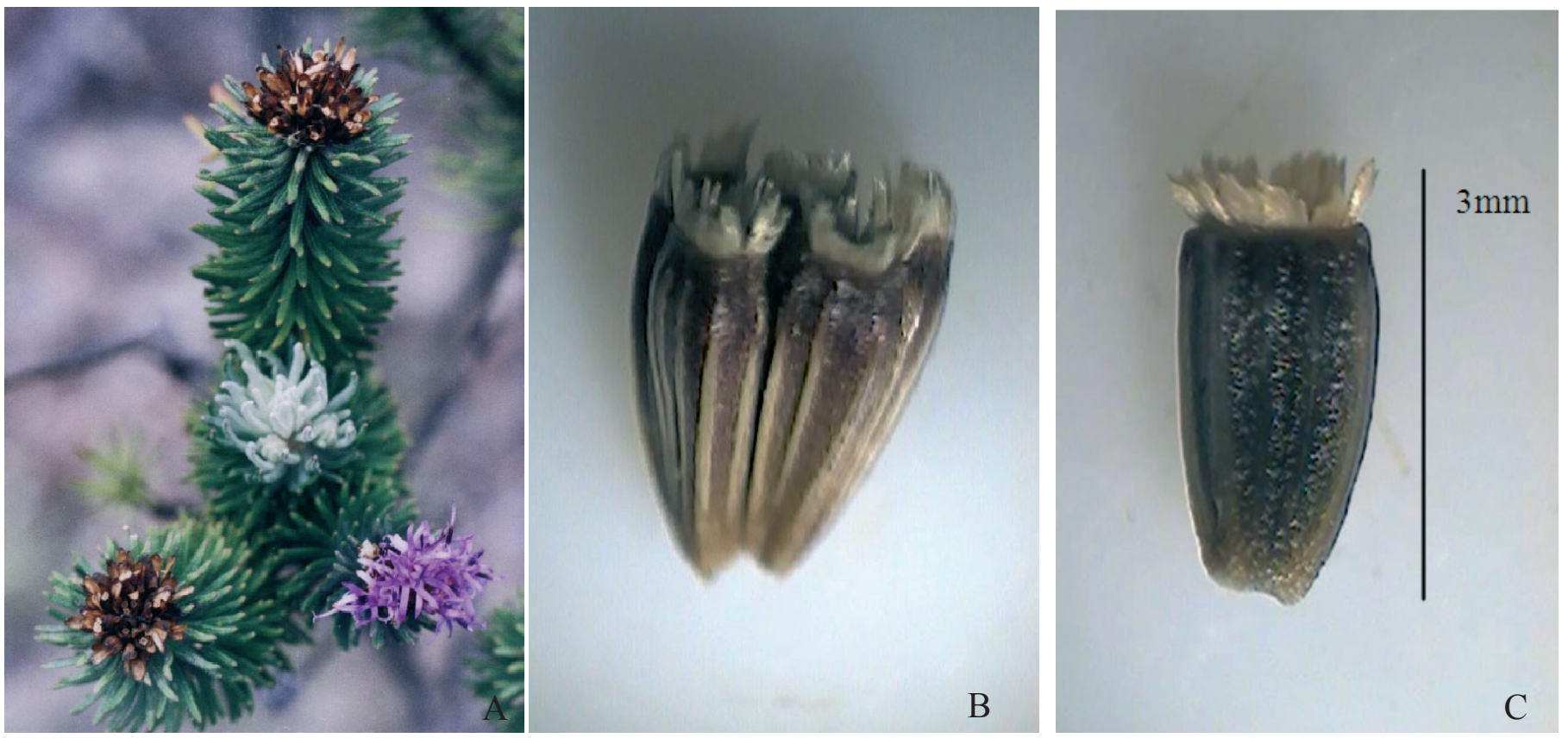

FIGURA 2. Caracterização do estádio 2 de coleta de aquênios de Lychnophora pinaster (arnica): capítulos com aquênios sem o papus interno, já em dispersão (A); aquênios agrupados, sem papus interno aderido, formando subcapítulo (B); aquênio sem papus interno aderido (C).

Após separação manual de aquênios dos capítulos, de uma pequena amostra, foi determinado o grau de umidade no momento da coleta, pelo método de estufa a $105^{\circ} \mathrm{C}$, durante 24 horas, conforme as prescrições das Regras para Análise de Sementes (Brasil, 1992). Foram utilizadas duas amostras de um grama para cada um dos estádios e os resultados foram expressos em porcentagem.

Subsequente à coleta, os capítulos foram submetidos à secagem em estufa de circulação de ar forçado, com temperatura variando de $25^{\circ} \mathrm{C}$ a $30^{\circ} \mathrm{C}$, por 72 horas, até a umidade aproximada de $10 \%$. Após a secagem, os capítulos foram debulhados e, juntamente com os aquênios eventualmente desprendidos, foram submetidos ao beneficiamento.

Os capítulos foram debulhados manualmente e, posteriormente, passaram por um processo de pré-limpeza utilizando-se um protótipo da máquina de ventiladores e peneiras para retirada das impurezas. Foi efetuado repasse para retirada do excesso do material indesejável. A massa do material obtido foi de $1.036,78 \mathrm{~g}$ para o estádio $1 \mathrm{e} 707,40 \mathrm{~g}$ para o estádio 2. Logo em seguida, utilizando um soprador vertical modelo South Dakota, marca De Leo, foi realizado o beneficiamento dos aquênios utilizando-se a abertura 3,75 com repasse, por um período de tempo de 2 minutos e 40 segundos. A massa final de aquênios apurados foi de 134,32g para o estádio 1 , correspondendo a $13 \%$, e $98,18 \mathrm{~g}$ para o estádio 2 , ou seja, $13,9 \%$, em relação a massa inicial do material antes do beneficiamento. Os aquênios obtidos foram utilizados nas determinações subseqüentes.

\section{Teste de raios $X$}

Adequação da técnica - Os aquênios foram dispostos sobre fita adesiva transparente de dupla face, aderida a uma placa de acrílico transparente, com dimensões $24 \mathrm{x}$ $18 \mathrm{~cm}$ e espessura de $2 \mathrm{~mm}$. Após montagem, a placa com os aquênios foi sobreposta ao filme radiográfico Kodak, Min-R 2000, tamanho 18 x $24 \mathrm{~cm}$ e submetida à radiação em equipamento de raios X Faxitron HP, modelo 43855A. Os filmes radiográficos foram revelados e analisados visualmente sobre transiluminador. Foram avaliadas, em testes preliminares, imagens radiográficas de aquênios submetidos a intensidades de 25, 30, 35 e $50 \mathrm{Kv}$, por 30, 45, 60 e 90 segundos de exposição.

Os aquênios foram separados em três categorias de acordo com a morfologia interna visualizada nas radiografias: aquênios cheios (semente ocupando totalmente a cavidade do aquênio), aquênios mal formados (apresentando estrutura rudimentar de semente no interior do aquênio) e aquênios 
vazios (ausência de semente no aquênio), de acordo com a ISTA (1999). Para ambos os estádios, após serem radiografadas e separadas por categorias, foram constituídas quatro repetições de 50 aquênios, sendo pesadas em balança digital $(0,0001 \mathrm{~g})$.

Teste de germinação - Os aquênios, após separação nas três categorias, foram dispostos sobre duas folhas de papel mata-borrão, previamente umedecidos com água destilada, com uma quantidade equivalente a 2,5 vezes a massa do substrato seco, acondicionados em caixas acrílicas do tipo "gerbox" e mantidas em BOD, à temperatura alternada de $20-30^{\circ} \mathrm{C}$ e iluminação de 12 horas associada à temperatura mais elevada. Foram utilizadas quatro repetições de 50 aquênios para cada tratamento.

Foi adotado o critério de emissão da raiz primária para o cálculo do índice de velocidade de germinação (IVG), utilizando-se a fórmula proposta por Maguire (1962). As avaliações foram realizadas em dias alternados. Para o teste de germinação adotou-se a porcentagem de plântulas normais, sendo as mesmas computadas e eliminadas periodicamente até 90 dias após a instalação do teste de germinação.

Decorrido o período do teste de germinação, foram retirados os aquênios remanescentes de cada repetição, sendo os mesmos seccionados transversalmente com o auxílio de uma lâmina e imersos em solução de sal de tetrazólio $(2,3,5$ trifenil cloreto de tetrazólio) a $0,5 \%$, por 24 horas, a $30^{\circ} \mathrm{C}$ no escuro. Após esse período e desenvolvida a coloração vermelha, os aquênios foram lavados em água corrente e examinados individualmente sob microscópio estereoscópico para a determinação da viabilidade.

Procedimento estatístico - O delineamento experimental utilizado foi inteiramente casualizado, com quatro repetições de 50 aquênios por tratamento, em esquema fatorial $2 \times 3$ ( 2 estádios $\times 3$ categorias). Os dados obtidos no teste de germinação foram transformados em $\sqrt{x+0,5}$, conforme proposto por Banzatto e Kronka (1995), submetidos à análise de variância e analisados pelo programa estatístico SISVAR. As médias foram comparadas pelo teste de Tukey em 5\% de probabilidade.

\section{RESULTADOS E DISCUSSÃO}

A intensidade de $30 \mathrm{Kv}$ e o tempo de exposição de 45 segundos, determinados em análises preliminares, permitiram melhor visualização e distinção dos aquênios. Na Figura 3, observam-se radiografias de aquênios de arnica, classificadas nas três categorias: cheios, mal formados e vazios.

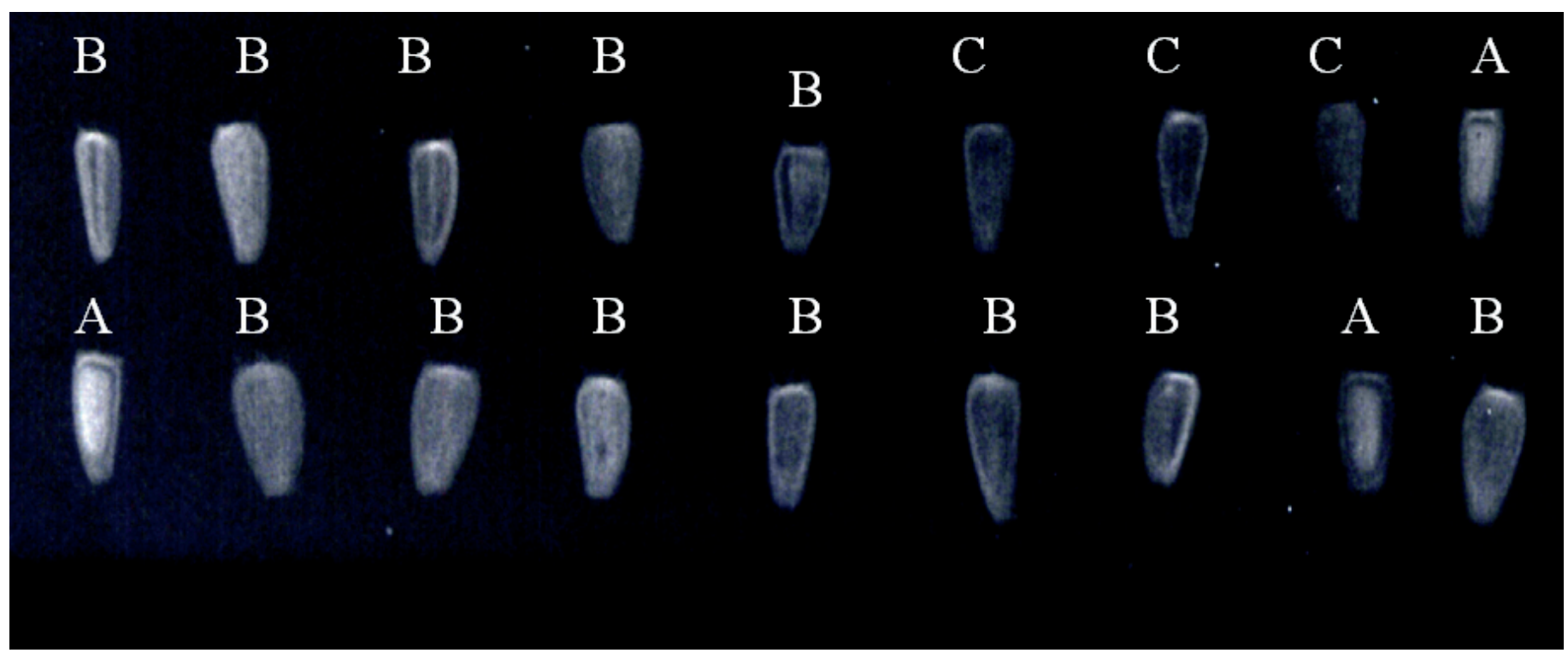

FIGURA 3. Radiografia de aquênios de Lychnophora pinaster (arnica): aquênios cheios (A); aquênios mal formados (B); aquênios vazios (C). 
Os aquênios de arnica apresentavam teor de água de, aproximadamente, $10 \%$, por ocasião da instalação do teste de germinação. A porcentagem e o índice de velocidade de germinação (IVG) dos aquênios de arnica das diferentes categorias variaram em função do estádio de maturação por ocasião da coleta. Já em relação à massa, não foi observada a dependência entre estes dois fatores, mas sim o efeito isolado de estádios de maturação e categoria de aquênio de acordo com a imagem radiográfica.

Os aquênios da categoria cheios, para ambos os estádios, apresentaram germinação superior às categorias mal formados e vazios, de $16,0 \%$ e $40,5 \%$ para os estádios 1 e 2, respectivamente (Tabela 1). O índice de velocidade de germinação (IVG) seguiu a mesma tendência, ou seja, a categoria de aquênios cheios se destacou quando comparada às categorias mal formados e vazios, tanto para o estádio 1 quanto para o estádio 2. Nos aquênios remanescentes no teste de germinação, analisados pelo teste de tetrazólio, observou-se que a categoria cheios possuía um número de aquênios que, embora não tivessem germinado, apresentavam-se ainda com viabilidade de $36,5 \%$ para o estádio 1 o que somado as plântulas normais do teste de germinação $(36,5+16,0)$ resultaram em 52,5\% de sementes potencialmente viáveis. Já para o estádio 2 foram detectadas $21 \%$ de sementes viáveis mais $40,5 \%$ de plântulas normais. Na categoria mal formados, aquênios colhidos no estádio 1 apresentaram $3,0 \%$ de viabilidade e no estádio 2 a viabilidade foi nula, sendo que, para os aquênios remanescentes, apenas $1,5 \%$ dos colhidos no estádio 1 e $0,5 \%$ do estádio 2 mostraram-se viáveis após a utilização do tetrazólio. Conforme esperado, os aquênios classificados como vazios não apresentaram germinação após 90 dias no teste de germinação, o que também foi comprovado pelo tetrazólio. Esses resultados demonstram a eficiência do teste de raios $\mathrm{X}$ na identificação de aquênios com maior probabilidade de germinação.

Considerando-se apenas os aquênios cheios, a germinação e o vigor dos aquênios no estádio 2 foram superiores em relação aos do estádio 1 . Infere-se, dessa forma, que o grau de maturação do embrião, dos aquênios coletados no estádio 1, poderia estar incipiente quando comparado ao estádio 2 já em dispersão, refletindo, assim, os menores valores obtidos. O efeito do estádio de maturação na qualidade fisiológica de lotes é evidenciado por autores como Carvalho e Nakagawa (2000), que destacaram a importância da coleta após as sementes terem alcançado o máximo de massa ou a maturidade fisiológica.
TABELA 1. Média de germinação (\%) e índice de velocidade de germinação (IVG) de aquênios de Lychnophora pinaster (arnica) coletados em dois estádios de maturação e separados em três categorias de acordo com análise radiográfica.

\begin{tabular}{ccccc}
\hline \multirow{2}{*}{ Avaliação } & Estádio & \multicolumn{3}{c}{ Categorias } \\
\cline { 3 - 5 } & & Cheios & $\begin{array}{c}\text { Mal } \\
\text { formados }\end{array}$ & Vazios \\
\hline \multirow{2}{*}{ Germinação } & 1 & $16,0 \mathrm{Ba} *$ & $3,0 \mathrm{Ab}$ & $0 \mathrm{Ab}$ \\
& 2 & $40,5 \mathrm{Aa}$ & $0 \mathrm{Ab}$ & $0 \mathrm{Ab}$ \\
\hline \multirow{2}{*}{ IVG } & 1 & $0,2262 \mathrm{Ba}$ & $0,0310 \mathrm{Ab}$ & $0,0000 \mathrm{Ab}$ \\
& 2 & $0,5390 \mathrm{Aa}$ & $0,0000 \mathrm{Ab}$ & $0,0000 \mathrm{Ab}$ \\
\hline
\end{tabular}

* Médias seguidas da mesma letra maiúscula na vertical e minúscula na horizontal, não diferem entre si, pelo teste de Tukey, em 5\% de probabilidade

Embora a germinação e o vigor tenham sido superiores nos aquênios cheios em relação a mal formados e vazios, para ambos os estádios, observa-se, na Figura 4, que os aquênios mal formados possuem massa semelhantes aos cheios, distinguindo-os dos aquênios vazios. Com esse fato, pode-se inferir que a utilização do soprador, de maneira isolada, não é eficiente para o beneficiamento dos aquênios de arnica, provavelmente pela pequena contribuição da massa da semente em relação à massa total do aquênio. Assim, é inviável a separação de aquênios com maior germinação, apenas com base na sua massa. Nesse contexto, Silva (1994) utilizando um método de separação por densidade proposto por Hammerton et al. (1989), conseguiu separar os aquênios chochos e mal formados dos aquênios cheios, obtendo, assim, alta germinação. Também, desenvolvendo um protocolo para a propagação assexuada da arnica, via cultura de tecidos, utilizando-se o embrião extraído dos aquênios, Souza et al. (2003) obtiveram sucesso utilizando o mesmo princípio de separação.

Os aquênios do estádio 2 apresentaram maior massa média $(0,0879 \mathrm{~g})$ em relação aos do estádio $1(0,0858 \mathrm{~g})$. Para determinadas espécies, as sementes ao atingirem o máximo de matéria seca, apresentam o máximo de germinação e vigor, sendo este considerado o ponto de maturidade fisiológica (Popinigis, 1985). Dentre outros fatores, isto pode ter contribuído para a maior porcentagem e índice de velocidade de germinação dos aquênios do estádio 2 em relação aos do estádio 1 . 


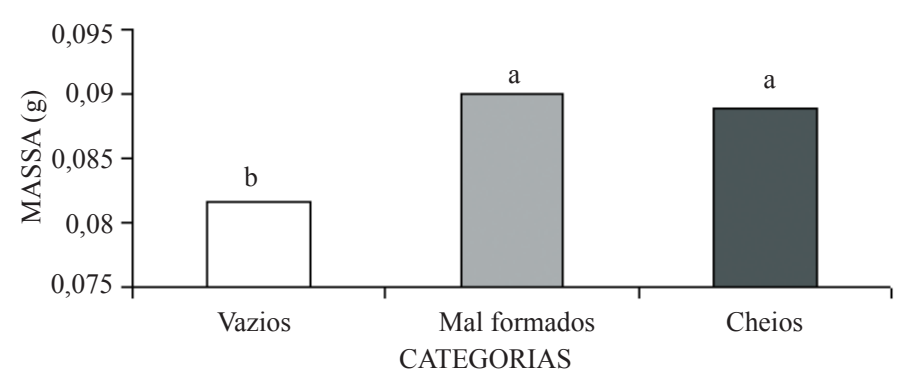

FIGURA 4. Média de massa (g) de 50 aquênios de Lychnophora pinaster (arnica) para cada categoria identificada com análise radiográfica.

Guimarães (1999) comentou que quando o teor de água encontra-se na faixa de $30 \%$ a $50 \%$ as sementes, de espécies ortodoxas, teriam alcançado o máximo de matéria seca e, para efeitos práticos, poderia ser considerada desligada da planta-mãe. No entanto, para a espécie em estudo, com a umidade de coleta aproximada de $30 \%$, no estádio 1 , os aquênios provavelmente ainda não tinham adquirido a maturidade fisiológica. Embora não se possa afirmar com exatidão o momento da abscisão, é provável que os aquênios, no estádio 1, ainda estivessem recebendo produtos de reserva em função da maior massa apresentada pelo estádio 2 , não caracterizando, portanto, desprendimento da planta genitora neste primeiro estádio.

Embora não se trate do estudo de todo o processo de maturação, os resultados subsidiam, de maneira condizente, a associação de caracteres morfológicos ao momento propício para a coleta de aquênios de arnica. Desta forma, a colheita de aquênios sem o papus interno, já em dispersão, pode ser considerada adequada para a arnica, embora já estivessem com $14 \%$ de umidade e, provavelmente, em equilíbrio higroscópico com o ambiente. Uma característica importante observada foi a não detecção de deiscência nos aquênios de arnica, ou seja, o aquênio não se abriu durante a dispersão, sendo considerado, dessa forma, indeiscente.

De acordo com Carvalho e Nakagawa (2000), em algumas espécies, as sementes adquirem a capacidade de germinação somente após um período de tempo relativamente longo. Como, neste ponto, o decréscimo no teor de água já está se processando de modo cada vez mais acentuado, a capacidade de germinação cresce de maneira ininterrupta até um ponto máximo, já que a probabilidade de que as sementes germinem no próprio fruto é bem menor.

Analisando-se a germinação acumulada dos aquênios cheios, nos dois estádios de maturação (Figura 5), observase que a lenta germinação ao longo do tempo pode estar associada à presença de algum mecanismo desenvolvido para a dormência. A germinação das sementes, segundo Carvalho e Nakagawa (2000), é uma característica que pode ser influenciada pelo fenômeno da dormência, tendo sua avaliação dificultada no teste de germinação. Nesse sentido, torna-se importante ressaltar que, em testes preliminares, foi constatada germinação em aquênios do estádio 2, mais maduros, após 9 meses da data de coleta. Os aquênios haviam sido colocados para germinar em temperatura $20-30^{\circ} \mathrm{C}$, com fotoperíodo de 12 horas associado à temperatura mais elevada, no mesmo dia da coleta, quando apresentavam em torno de $14,0 \%$ de umidade e não haviam sido submetidos à secagem.

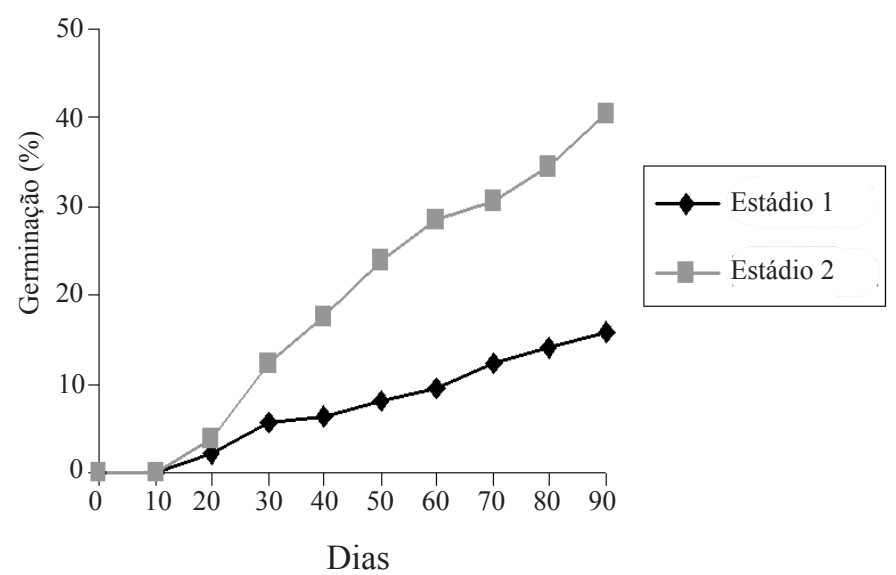

FIGURA 5. Germinação acumulada de aquênios de Lychnophora pinaster (arnica), para categoria aquênios cheios, em dois estádios de maturação, no período de 90 dias.

Por outro lado, observando-se o aquênio, nota-se também que o pericarpo possui uma estrutura que pode ocasionar algum impedimento à entrada de água ou oxigênio na semente (Figura 6), inibindo ou retardando a germinação ao longo do tempo. Em espécies não domesticadas, como no caso da arnica, a germinação das sementes no tempo é uma estratégia de perpetuação da espécie para adaptação e tolerância às adversidades ambientais. A deuniformidade no florescimento e, conseqüentemente, da maturação dos aquênios, contribui com esse fato. Segundo Marcos Filho (2005) a posição das sementes na planta-mãe é um dos aspectos que pode influenciar os diferentes graus de dormência, fenômeno esse denominado heteroblastia ou polimorfismo, e que contribui para a distribuição da germinação no tempo. Embora o 
controle deste polimorfismo ainda não seja compreendido, observa-se em espécies da família Asteraceae que a posição dos aquênios nos capítulos ou na planta-mãe durante a maturação pode afetar o grau de dormência (Bryant, 1989).

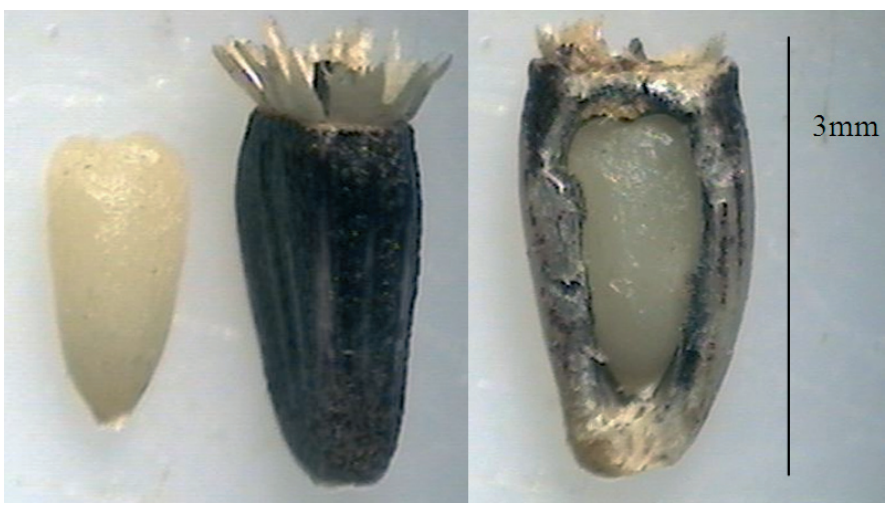

FIGURA 6. Aspecto da semente, aquênio e pericarpo de Lychnophora pinaster (arnica).

\section{CONCLUSÕES}

A exposição de aquênios de arnica aos raios $X$, na intensidade de $30 \mathrm{Kv}$ por 45 segundos, permite a sua separação em categorias, de acordo com sua morfologia interna.

A época ideal para a coleta de aquênios para a propagação de arnica ocorre por ocasião da dispersão do papus interno.

\section{AGRADECIMENTOS}

A FAPEMIG e CNPq pelo apoio financeiro.

\section{REFERÊNCIAS}

BANZATTO, D. A.; KRONKA, S. N. Experimentação agrícola. 3. ed. Jaboticabal: Funep, 1995. 247 p.

BINO, R. J.; AARTSE, J. W.; VAN DER BURG, W. J. Nondestructive X-ray analysis of Arabidopsis embryo mutants. Seed Science Research, v. 3, n. 3, p. 167-170, 1993.

BRASIL. Ministério da Agricultura e Reforma Agrária. Regras para análise de sementes. Brasília, DF: SNDA/ DNDV/CLAV, 1992. 365 p.

BRYANT, J. A. Fisiologia da semente. São Paulo: EPU, 1989, 86 p.

CARVALHO, M. L. M.; OlIVEIRA, L. M. Raios X na avaliação da qualidade de sementes. Informativo ABRATES, Pelotas, v.16, $n^{\text {os }}$. 1, 2, 3, p. 93-99, 2006.
CARVALHO, N. M.; NAKAGAWA, J. Sementes: ciência, tecnologia e produção. Jaboticabal: FUNEP, 2000. 588 p.

GUIMARÃES, R. M. Fisiologia de Sementes. Lavras: UFLA/FAEPE, 1999. $79 \mathrm{p}$.

HAMMERTON, R. D.; SMITH, M. T.; VAN STANDEN, J. Factors influencing seed variability and germination in Hypoxis hemerocallidea Fisch \& Meyer. Seed Science and Technology, v. 17, n. 3, p. 613-624, 1989.

INTERNATIONAL SEED TESTING ASSOCIATION (ISTA). International Rules for Seed Testing. Seed Science and Technology, v. 27, 333p. 1999. Supplement.

MACHADO, C. F.; CICERO, S. M. Aroeira-branca (Lithraea molleoides (Vell.) Engl. - Anacardiaceae) seed quality evaluation by the X-ray test. Scientia Agricola, v.60, n.2, p.393-397, 2003

MAGUIRE, J. D. Speed of germination aid in selection and evaluation for seedling and vigour. Crop Science, v. 2, n. 2, p. 176-177, 1962.

MARCOS FILHO, J. Fisiologia de sementes de plantas cultivadas. Piracicaba: FEALQ, 2005. 495 p.

OLIVEIRA, L. M.; CARVALHO, M. L. M.; DAVIDE, A. C. Utilização do teste de raios $X$ na avaliação da qualidade de sementes de canafístula (Peltophorium dubium (Sprengel) Taubert. Revista Brasileira de Sementes, v.25, n.1, p.116120, 2003.

OLIVEIRA, L. M.; CARVALHO, M. L. M.; GUIMARÃES, R. M.; MASETTO, T. E. Avaliação da qualidade de sementes de Tabebuia serratifolia VAHLNICH. e T. impetiginosa (MARTIUS EXA. P. DE CANDOLLE) STANDLEY (Bignoniaceae) pelo teste de raios X. Revista Brasileira de Sementes, v.26, n.2, p.138-143, 2004.

POPINIGIS, F. Fisiologia da semente. 2. ed. Brasília, DF: AGIPLAN, 1985. 289 p.

RODRIGUES, V. E. G.; CARVALHO, D. A. de. Plantas medicinais no domínio dos cerrados. Lavras: UFLA, 2001. $180 \mathrm{p}$.

SEMIR, J. Revisão taxonômica de Lychnophora Mart. (Vernoniaceae: Compositae). 1991. 515 f. Tese (Doutorado em Biologia Vegetal) - Universidade de Campinas, Campinas, 1991.

SILVA, S. M. P. Aspectos da fenologia e da reprodução sexuada da arnica (Lychnophora pinaster Mart.) Asteraceae. 1994.45f.Dissertação(Mestrado)-Universidade Federal de Lavras, Lavras.

SIMAK, M.; GUSTAFSSON, A. X-ray photography and 
sensitivity in forest tree species. Hereditas, v. 39, n. 3/4, p. 458-468, 1953.

SOUZA, A. V. de.; PINTO, J. E. B. P.; BERTOLUCCI, S. K. V.; CORRÊA, R. M.; CASTRO, E. M. de. Germinação de embriões e multiplicação in vitro de Lychnophora pinater
Mart. Ciência e Agrotecnologia, v.27, p.1532-1538, dez., 2003. Edição Especial.

TONETTI, O. A. O.; DAVIDE, A. C.; SILVA, E. A, A. Qualidade física e fisiológica de sementes de Eremanthus erythropappus (DC.) MAC. LEISH. Revista Brasileira de 